\title{
Ethnomedicinal plants used by the people of Manang district,
} central Nepal

\author{
Shandesh Bhattarai*1, Ram P Chaudhary ${ }^{1}$ and Robin SL Taylor ${ }^{2}$
}

Address: ${ }^{1}$ Central Department of Botany, Tribhuvan University, Kirtipur, Kathmandu, Nepal and ${ }^{2}$ Department of Community Medicine, McGill University, Montreal, QC, Canada

Email: Shandesh Bhattarai* - bhattaraishandesh@yahoo.com; Ram P Chaudhary - ram@cdbtu.wlink.com.np; Robin SL Taylor - rsltaylor@alumni.ucalgary.ca

* Corresponding author

Published: 04 October 2006

Journal of Ethnobiology and Ethnomedicine 2006, 2:4I doi:|0.| I86/|746-4269-2-4 I
Received: 18 June 2006

Accepted: 04 October 2006

This article is available from: http://www.ethnobiomed.com/content/2/I/4I

(c) 2006 Bhattarai et al; licensee BioMed Central Ltd.

This is an Open Access article distributed under the terms of the Creative Commons Attribution License (http://creativecommons.org/licenses/by/2.0), which permits unrestricted use, distribution, and reproduction in any medium, provided the original work is properly cited.

\begin{abstract}
Background: The district of Manang $(2000-6000 \mathrm{~m})$ is located in the Central Himalayas, Nepal. The majority of local inhabitants of the area are Gurungs, of Tibetan origin. The remoteness of the region has resulted in continued use of plants as medicine in an area where the ethnobotany has sparsely been documented.

Methods: Interviews were conducted with amchi (Tibetan medicinal practitioners), local healers (including priests locally known as 'lamas'), plant traders, and knowledgeable villagers (including herders) regarding local plant names and their medicinal uses during several field visits (20022005). When convenient to the locals, a jungle or forest walk was done with the healers, allowing for both plant collection and detailed information gathering.

Results: This present research documented 91 ethnomedicinal plant species, belonging to 40 families under 73 genera, and 45 new ethnomedicinal plant species are added. These 91 locally used medicinal plants are found to treat 93 ailments. This study provides information on 45 plant species previously unknown for their medicinal uses in Manang. The indication for use, mode of preparation, dose and administration of medicine are described in detail for each species.

Conclusion: This wealth of ethnobotanical knowledge persists, and is being transferred to the next generation in some areas in upper Manang, in a country where this is often not the case. The senior amchi of the area (Karma Sonam Lama), who has been practicing Tibetan medicine for three generations, feels that it is of utmost importance to conserve the traditional healing system and to pass his knowledge on to the local community about the importance of medicinal plants. He hopes that this will lead to the conservation and sustainable management of medicinal plants in the villages. Over the duration of this research, the prices of several rare medicinal plants of Manang increased dramatically, highlighting both the scarcity and the quick disappearance of the species. This is only one example of a worrying trend of over harvesting of medicinal plants, and highlights the need for conservation and management of medicinal plants of Manang district.
\end{abstract}

\section{Background}

The use of plants as medicine is widespread throughout the world. In many areas of rural Nepal, medicinal knowledge and practice are passed down entirely through the 
oral tradition and personal experience [1]. The total population of Nepal is 23.1 million [2], and about $90 \%$ of the Nepalese people reside in rural areas where access to government health care facilities is lacking. It is estimated that there is one physician for 30,000 people whereas there is one healer for fewer than 100 people in Nepal [3]. Many studies have investigated the uses of medicinal plants in Nepal [4-13], although only two studies [8,14], have been done to document the knowledge about the plants in Manang district. In the present study, a detailed ethnomedicinal survey was carried out in the Neyshang, Nar and Phoo regions of Manang district. This present research adds to that knowledge base, and this paper will be helpful to document important medicinal plants of the Nepal Himalayas in the trans-Himalayan Zone, which are often used by the Gurung communities for primary healthcare.

The district of Manang (2000 - $6000 \mathrm{~m}$ ) is located in the Central Himalayas Nepal. The Gurungs of Tibetan origin live in the area [15].The inhabitants of Nyeshang are known by the name of Nyeshangba or, more popularly, by the name of Manangba and of Nar and Phoo by the name of Narba [16]. Manang district lies in the Annapurna Conservation Area Project (ACAP), and the permission for the field study, as well as the collection of voucher specimens was received from the headquarters of the Annapurna Conservation Area Project (ACAP) in Pokhara. Manang district is ranked in $10^{\text {th }}$ position among 75 districts in Nepal on overall development index [17]. The trans-Himalayan range is a unique chain of mountains with fragile ecosystems but the diversity of wild flora and fauna fulfills basic daily needs for the peoples living in the mountains and plains [18].

In Manang district herbal medicine preparations are used to treat a variety of different ailments, from cough and cold, to respiratory diseases to dyspepsia. Access to health care is often a problem in remote districts of Nepal, and Manang district is no exception. The only means of trustworthy transport in the district are chartered helicopters, or to travel by foot, which takes three days to reach to Chame, the district headquarters, from Beshisahar (Lamjung district), the road-head town. Because of the specific geographical features of Manang district, and the lack of government health facilities in the district, the people are largely dependent on the indigenous health care system. Local herbs and other plant resources found in that area are the principal source of medicine, and are prescribed by traditional healers as medicines. This is often the only source of primary health care in the district of Manang.

\section{Materials and methods Plant collection and identification}

The plants were collected in and around the villages of Pisang, Hungde, Munji, Ghyaru, Ngawal, Braga, Manang, Tanki Manang, Khangshar; and places such as Tilicholake, Kecholake, Yakshed, Goatshed, Nar and Phoo in the Manang District of Central Nepal from 2002-2005 two times in each year (first in July/August, and second September/October). The study area is shown in Figure 1, Map of the study area (Manang district), Central Nepal. The district headquarters, Chame, is noted, as well as the remote villages of Nar and Phoo, which have recently opened for trekking.

Plants were selected because of their use mainly among the Gurungs of Tibetan origin. Only species that were consistently used to treat the same illness by several healers and villagers were selected. The herbarium specimens were identified by two of us (S.B. and R.P.C.) with the help of standard literature [19-23], and nomenclature of the identified species follows standard literatures [24-27]. A set of voucher herbarium specimens with voucher numbers was made for each collection and have been deposited in the Tribhuvan University Central Herbarium (TUCH) Nepal.

\section{Interviews with the healers}

The traditional healers in upper Manang comprise amchi (Tibetan medicinal practitioner), local healers (that include priests locally known as 'lamas'), plant traders, and knowledgeable villagers (including herders). Informed consent was obtained verbally from each healer or villager before they were interviewed. They were interviewed with their consent to have their names and knowledge published; and are Mukhiya Ghale, 64 years, male; Chakki Gurung, 61 years, female; Dipli Gurung, 52 years, male; Kancha Bishwakarma, 50 years, male; Kalu Gurung, 50 years, male; Karki Gurung, 67 years, male; Aoda Bishwakarma, 45 years, male; Kali Gurung, 46 years, male; Galchen Gurung, 57 years, male; Kazi Gurung, 31 years, male; Sonam Chhiring, 27 years, male; Kalu Gurung, 27 years, male; Karma Gurung, 45 years, male; Sengla Gurung, 66 years, male; Chhiring Gurung, 50 years, male; Karma Sonam Lama, 68 years, male; Lopsang Lama, 42 years, male; and Polchom Lama, 21 years, female.

Two interviewing methods were followed. The first was the 'specimen display' method. After collecting plant specimens, these species were shown to the traditional healers in order to elicit any medicinal information. The same plant specimens were shown to the different healers to confirm the accuracy of the results. When convenient to the locals, the second method of jungle or forest walk took place. A walk through the forest with the healers 


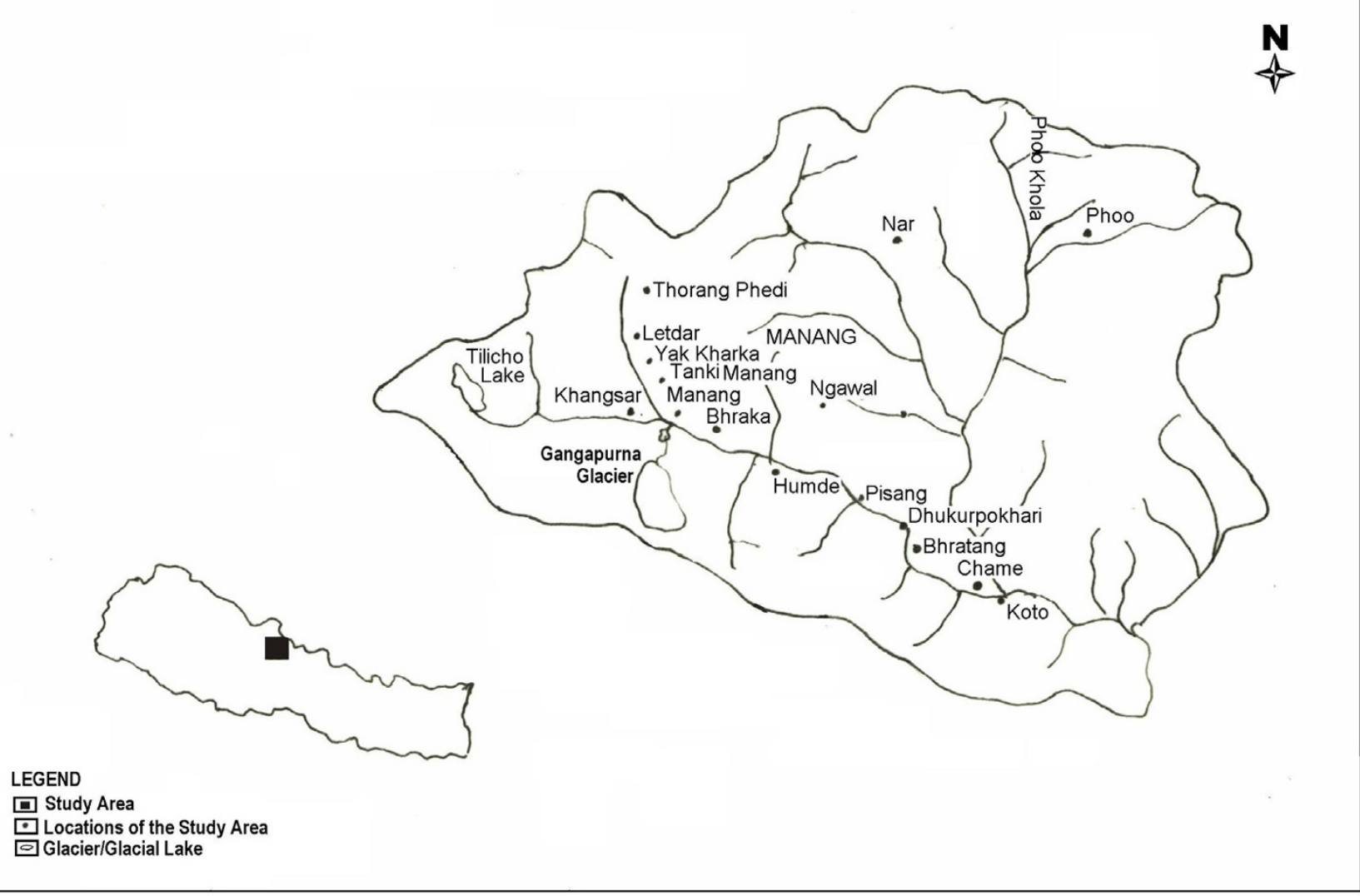

Figure I

Map fo the study area (manang district), Central Nepal.

allowed for both plant collection and detailed information gathering.

\section{Results and discussion}

The results of the present study are presented [see Additional file 1] with alphabetical arrangement of plant scientific name (in italics) followed by family name (in capital letters), voucher number, local names (Gurung/amchi/ Nepali) and detailed uses (mode of preparation doses and administration of medicine). Altogether 91 plant species belonging to 40 families and 73 genera are reported from the study area. The largest number of species were noted from the families Composite (10 species), followed by Ranunculaceae (8 species), Labiatae (5 species). Three family Polygonaceae, Umbelliferae, and Rosaceae represent four plant species each. Five families, Amaryllidaceae, Liliaceae, Gentianaceae. Berberidaceae, and Boraginaceae represent three plant species each. Twelve families, including Pinaceae, Saxifragaceae, Solanaceae, Araceae, etc., were represented by two plant species each. Eighteen families including Morchellaceae, Taxaceae, Clavicipitaceae, etc., were represented by one plant species each. These 91 locally used medicinal plants are found to treat 93 ail- ments. Therefore, the exhaustive study of medicinal plants within the upper Manang (Neyshang and Nar-Phoo) reflects its rich diversity and history of medicinal plant use.

Although Manandhar (1987) documented 81 species of plants under 75 genera of 32 families, 45 new ethnomedicinal plants were added by the present results. Twentythree plant species including Cicerbita macrorhiza, Cynoglossum zeylanicum, Rhododendron lepidotum, Rosa macrophylla, Rosa sericea, Rubus foliolosus, Rumex nepalensis, etc., were common ethnomedicinal plants in the above and the present results; however, additional uses were also noted in the present results. Pohle (1990) documented 239 species of plants, of which 66 species of plants were used ethnomedicinally. Compared with Pohle (1990), the present results added 60 new species of plants which were used ethnomedicinally in the same area. Thirty-one plant species were found to have the same ethnomedicinal uses as documented by Pohle, but the present investigation finds more uses of those same plants. When comparing both Manandhar (1987) and Pohle (1990) to the present results, 45 plant species are newly docu- 
mented for their ethnobotanical usage. Those newly added plant species are noted with asterisks $\left({ }^{*}\right)$ [see Additional file 1]. It is hoped that these newly documented plants may be valuable for future research activities. This initial documentation was the first step of bioprospecting of medicinal plants of Manang. Perhaps further steps in bioprospecting with regards to these medicinal plants will be beneficial for the discovery of new drugs/medicines.

When the present results are compared to the Tibetan literature [28] 72 ethnomedicinal plant species were newly recorded and 19 plant species including Mirabilis himalaica, Fragaria nubicola,Arisaema flavum, Arisaema jacquemontii etc., were found to have the same ethnomedicinal results. Comparison to Ayurvedic literature [29] showed that 83 species documented here are new. The eight species that had known Ayurvedic uses are commonly used in Manang: Berberis aristata, Cannabis sativa, Carum carvi, Ephedra gerardiana, Nardostachys grandiflora, Neopicrorhiza scrophulariiflora, Rhododendron anthopogon and Valeriana jatamansii.

This study found that many different parts of the medicinal plant species are used as medicine (namely as flowers, leaves, root, stem, whole plant, fruits, seeds, bark, latex, and cones) but the most commonly used plant part was flowers (used in 31 species), followed by leaves (30 species), root (26 species), stem (17 species), whole plant (14 species), fruits (11 species), seeds (7 species), bark (7 species), latex ( 3 species), and cones ( 1 species). It would follow that these plant parts have been selected because vulnerable flowers, leaves, and roots may contain more active principles in comparison to fruits, seeds, bark, and latex. Leaves, roots, stems and flowers are physically more vulnerable than bark or cone, and therefore it is not surprising that they contain more chemical defence compounds in the form of biologically active secondary metabolites.

Medicines are prescribed in different forms including powder, paste, decoction (liquid obtained from boiling or the medicinal plants in the solvent), and infusion (plant powder/paste mixed with the solvent). In this study, powders and decoctions were found to be used more often in comparison to pastes and infusions. Medicines are prescribed in both ways, as a single drug and in mixed ingredient form. In mixtures, several to many valuable medicinal plants are mixed with the other (often local) medicinal plants in standard amounts. The mixture is not changed depending on the person but the dose may be changed with age. Only herbal treatments were considered for this paper, leaving animal and mineral treatments for possible future research. Out of the 91 plant species, 25 species are used to cure only one disease and the remaining 66 plant species are used to cure more than one disease. A detailed list of these ailments can be seen in Table 1.

Plant parts were generally prepared as medicine using hot and cold water as the 'solvent', but occasionally remedies were prepared with milk, honey, oil and ghee. It is interesting and important to mention that medicines are

Table I: Lists of ailments treated by local traditional healers in Manang district, Central Nepal, grouped by body system.

\begin{tabular}{|c|c|}
\hline Body System (Categories) & Ailments treated by the local traditional healers \\
\hline Skin & $\begin{array}{l}\text { warts, wound problems (infections), wounds on skin, abrasions, skin swelling, boils, scabies, cuts and wounds, } \\
\text { burns, ringworm, and blisters }\end{array}$ \\
\hline Cardiovascular & heart disease, heart pain \\
\hline Respiratory & $\begin{array}{l}\text { shortness of breath, sore throat, chest pain, asthma, bronchitis, reduce sound production (wheezes or stridor) } \\
\text { during breathing, tuberculosis }\end{array}$ \\
\hline Neurological & numbness of limbs, paralysis, pulse pain, and 'vein pain' \\
\hline Reproductive & $\begin{array}{l}\text { infertility, wounds in vagina 'Bhringhee', quicken labour and delivery, stop bleeding during child birth and to } \\
\text { increase sexual power }\end{array}$ \\
\hline Gastointestinal & $\begin{array}{l}\text { diarrhoea, dysentery, vomiting, stomachache, gastritis, worms (white intestinal worms), anthelmintic, bile } \\
\text { disorders, constipation and stomach ache }\end{array}$ \\
\hline Orthopaedic & Heal broken bones, bone fracture, back pain, fracture of hand and leg, bone pain, bone diseases, joint pain \\
\hline Blood & $\begin{array}{l}\text { Increases the blood, purification of blood, menstrual disorders (heavy flow), menstrual problems, high blood } \\
\text { pressure and blood circulation }\end{array}$ \\
\hline Renal/Urological & Kidney diseases, urinary tract infection, diuretic, dysuria. \\
\hline Muscular & Increase body size, for body massage, 'waist pain', inflammation of body, rheumatism, neck pain, and limbs pain \\
\hline ENT & $\begin{array}{l}\text { conjunctivitis, pain in nose (internal or external), eye pain, stop bleeding from nose, eye diseases, blindness, defects } \\
\text { in visions, ear pain, sinusitis, gingivitis, relief tooth pain, cough and cold, and tonsillitis, }\end{array}$ \\
\hline Paediatric & massage the head of children \\
\hline Other/ Whole body/ Systemic & $\begin{array}{l}\text { fever (any kind of fever i.e., typhoid fever, malaria), jaundice, headache, high altitude sickness, vertigo/ dizziness, } \\
\text { stop sweating, diabetes, cancer, snake bite and scorpion sting, vitamin, nutritious, tonic (to treat weakness), } \\
\text { infectious diseases, rib pain (Kokho dukhnu), tuberculosis, edema (swelling of the body), body pain, and pain from } \\
\text { swelling }\end{array}$ \\
\hline
\end{tabular}


sometimes prepared with ghee (butter from a female Himalayan cow) when a patient has fever. For example Aconitum naviculare is used for fever and jaundice. Half spoonful of powder (made from dried whole plant) is mixed with 2 spoonfuls of Chauri ghee (butter from a female yak) and taken two times a day for fever and jaundice until recovery. This is a unique method of treatment of the fever patient. This local tradition was explained as to have started to 'sweeten' the taste of bitter Aconitum naviculare. This is interesting as doctors in Nepal often prohibit the use of oil for cooking when the patient has fever.

The more common use of water in the preparation of medicine could be due to reduced availability of other infusion materials such as milk, honey, oils and ghee in the rural villages. Milk and ghee are expensive to buy if a family does not own the animals. This does not explain the use of milk as a solvent. Water and milk have different properties and milk, containing fats, will dissolve chemicals that water will not. Perhaps some plants are mixed with milk to free chemicals that are not water soluble.

Medicinal plant use in Manang is not restricted to local plants. The amchis of Manang import several valuable medicinal plants from the lower regions of the district including the Terai (southern plains) region for the preparation of medicine. These include such as Rouvolfia serpentine, Phyllanthus emblica, Terminalia bellirica, and Terminalia chebula. Many valuable medicinal plants of Terai are known to the amchis and many are also mentioned in the Tibetan medical literature. An amchi will always collect local medicinal plants himself/herself. They stress that this is important because they have the experience to identify the plants. They worry that a misnamed or falsely collected sample may be dangerous for the patient.

Amchis may also create confidential mixtures of medicines for a patient. This confidentiality was maintained and no data regarding those mixtures were recorded. When permission was granted, the plants species has been indicated (for example [see Additional file 1]) with the confidential nature of the mixture noted. Many plant species are used by amchis to treat a broad range of ailments, while some plant species are found to treat only one aliment. For example, Allium oreoprasum, Aster diplostephioides, and Neopicrorhiza scrophulariiflora treat broad range of ailments, while Maharanga bicolour,Maharanga emodi, etc., are used to treat only one ailment (ear pain). In total, 91 medicinal plants were found to be used to treat 93 ailments. The most commonly treated ailments include gastritis, cough and cold, edema, stomachache, diarrhoea, dysentery, jaundice, rheumatism (disease characterized by inflammation of joints, muscles or connective tissue), and numbness of limbs.
The health care system in Manang district is basic. Few allopathic medicines are available, with the exception of paracetamol (acetaminophen) and bruffin (ibuprofen). For this reason, and because of traditional and cultural customs and beliefs, many people rely on local healers or amchis for health care. The amchis have great knowledge about the use of medicinal plants, and the villagers rely heavily on them, and so are not without health care. Interestingly, not only do the people of Nar and Phoo depend on amchis for health care, but patients from surrounding villages come to the village of Phoo, the site of a monastery with much respected amchis, for treatment. Figure 2 shows the Monastery of Phoo. For example, one patient (who agreed to the use of her story as long as her name was not used) from Tilche (of lower Manang village), travelled to the monastery for the treatment of dysfunctional vaginal bleeding. She had sought treatment in several places in Nepal and in India but her condition had not improved. The amchi gave a confidential mixture, prepared especially for this patient, continuously for a week. After the treatment the patient recovered and returned to her home. This account echoes the trust and respect that the peoples of Manang district have for the traditional healers and amchis for primary health care.

The remote village of Phoo, where this amchi practices, contains only 28 houses; and from these houses, 23 people are now working outside the country after having been trained by the most senior amchi (Karma Sonam Lama). It is very easy to leave the country after completing this training, as healers trained by this senior amchi are sought after. Both women and men come to the monastery to seek training.

The senior amchi is also familiar with the very intricate rules for collecting plants for use as medicines, such as time of collection, parts to be collected, and care in the conservation and management aspects of medicinal plants. He feels that it is of utmost important to conserve the traditional healing system and aware the local community about the importance of medicinal plants which will lead them to the conservation and management of medicinal plants in the villages. If this healing system cannot be conserved and utilized, he feels that in time it will have a negative effect on the whole community. He feels fortunate that his son, Lopsang Lama (age 42 years) and his daughter, Polchom Lama (21 years) are learning the traditional healing system from their father, and are acquiring a deep understanding of the use of medicinal plants. Many plant species of Manang district are used for medicine, several are very popular and known throughout Nepal.

Two species of Hippophae are included in this group of important medicinal plants. Hippophae salicifolia fruit is 


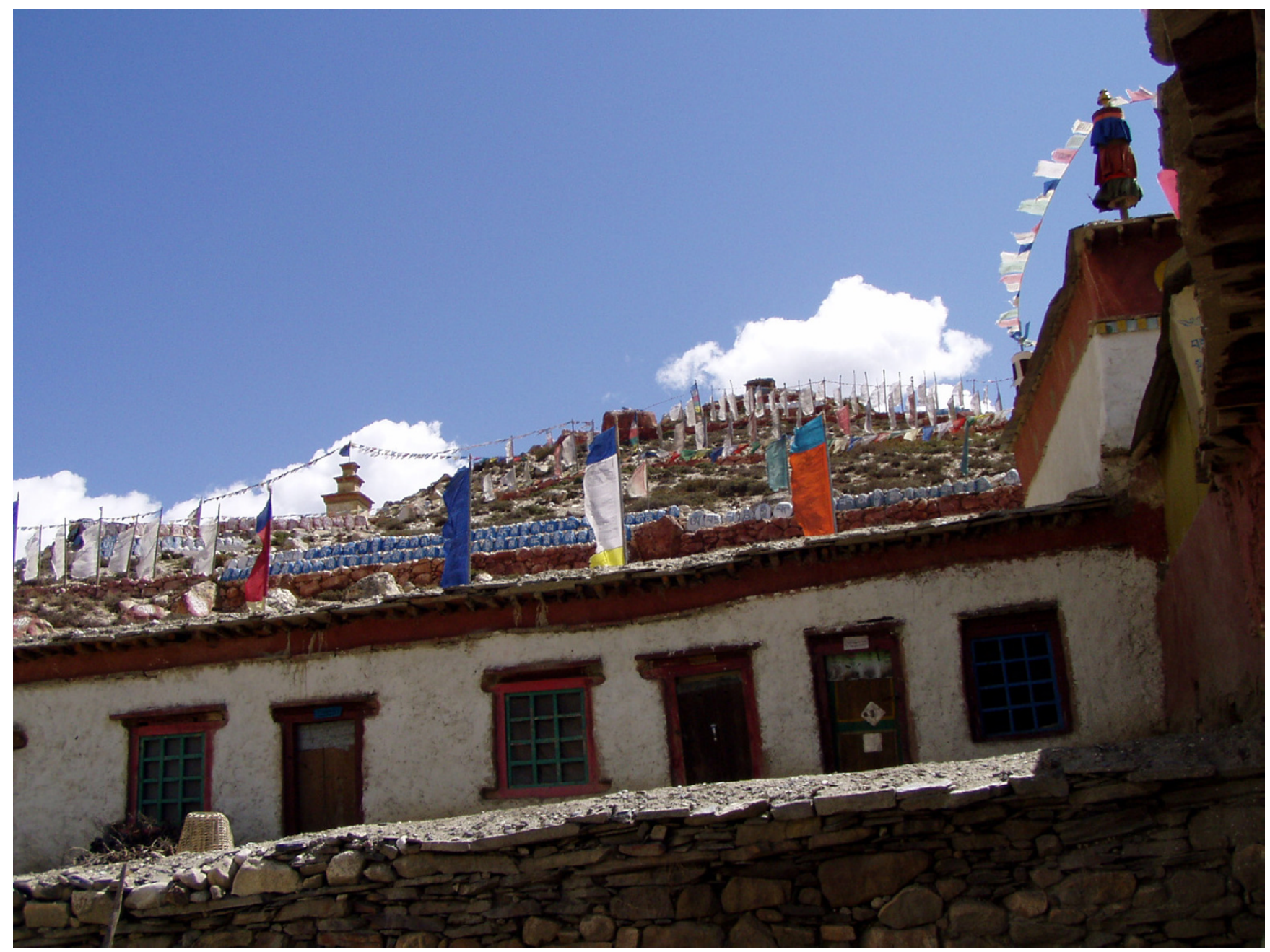

Figure 2

Monastery of Phoo

used for cough and cold, chest pain, stomachache, diarrhoea, dysentery, worms, rheumatism and gastritis and Hippophae tibetana fruit is used as a diuretic, tonic, cough and cold, to treat periods of weakness, and worms. These two species are used to treat broad range of ailments. It is very important to take immediate steps towards conservation and management aspects of these two important medicinal plants of Manang. Cultivation of these two species in the barren lands helps in conservation and management, while at the same time can improve the economic status of poorer people. Several development projects use fruits to make a now popular juice in the districts of Manang and Mustang, commonly called 'Seabuckthorn juice'.

Several medicinal plants are collected not just to be used locally, but also to sell to supplement earnings of the local people. Healers, amchis, local people and people of
Gorkha district who come to Manang to earn their livelihood collect highly prized medicinal plants including Allium oreoprasum;Cordyceps sinensis; Dactylorhiza hatagirea; and Neopicrorhiza scrophulariiflora.

Collection of the protected medicinal plant Cordyceps sinensis (Yartsagumba) is increasing these days in Manang. It has been banned for export to foreign countries except after processing within the country and with the permission of the Department of Forests. Collectors of Cordyceps sinensis stay for a month or two (May-June) in the Yakshed region, over $4500 \mathrm{~m}$ above sea level, in the areas of Kecho Lake (Icelake area), Khangshar, Braka, Hungde, Nar and Phoo. Cordyceps sinensis is sold for 34-45 Rupees/piece (equivalent to US $\$ 0.50$ ) to local healers, and local medicinal plant sellers. The local healers and amchis use it to make medicine, while plant sellers take it to Kathmandu and/or Pokhara and sell it for double or triple the price it 
sells for in Manang. Over the duration of this field research, (from 2002-2005) the going rate of one piece of Cordyceps sinensis increased from NRs 25 to 85 (equivalent to US\$1.25). This sudden increase in the price of this highly used medicinal plant highlights both their scarcity and the quick disappearance of the species. This is only one example of a worrying trend of over harvest of medicinal plants, and highlights the need for conservation and management of medicinal plants of Manang district.

\section{Conclusion}

The present survey concludes that the local population of Manang district has a fairly extensive and detailed knowledge regarding wild plants and their utility. The inhabitants of Nyeshang, Nar and Phoo in Manang district are ethnobotanically very rich. They have a wide knowledge on the use of plants for various purposes, including medicinal, food, fuel-wood, fodder, timber, household article, incense, etc., With regards to the uses of plants as medicines, this research confirms the vast knowledge of the traditional healers such as amchis, local healers and village elders on the subject of plants used for medicinal purposes.

Several factors may contribute to the persistence of this knowledge. The lack of modern and government facilities and remote geographical features of Manang district, as well as a strong belief in folk medicines continue the preference for traditional healers for their health care. This tradition is strong in the remote villages of Nar and Phoo, where the amchi is the only source of primary health care. Generally, most village elders can treat minor diseases themselves, using local medicinal plants. If they cannot treat the illness by themselves, they will seek help from the senior amchi (Karma Sonam Lama) of Phoo. There are other more junior healers and traditional medicinal plant sellers in the village of Phoo, but none more expert than the senior amchi.

The senior amchi of Phoo is grateful that his children are interested in learning how to use medicinal plants. It is common in the area to have a lack of flow of indigenous knowledge from elder to younger generation, since the young generation is reluctant to learn about traditional medicinal practices. The younger generation often leave their villages because of the profound economic changes that have come about during the last ten years. Many young families have left Manang and established themselves in the cities of Kathmandu or Pokhara.

In the quest to increase earnings, important medicinal plants are now being harvested for profit, which may put some species at risk. For example large amounts of Cordyceps sinensis are collected each year in the district. The continuation of collection of Cordyceps sinensis in the same area each year will decrease the population of the species and the locals worry that plants are rarer now and the species disappearing from the district. Indigenous practices and knowledge regarding the sustainable harvest and utilization of plant resources as medicine should be documented and preserved before they disappear.

\section{Competing interests}

The author(s) declare that they have no competing interests.

\section{Authors' contributions}

Author SB performed the interviews with the healers, identified the herbarium specimens with RPC and drafted and finalized the manuscript with RPC and RSLT. Author RPC joined SB to perform interviews, identified herbarium specimens with $\mathrm{SB}$, supervised the research works and finalized the manuscript with SB and RSLT. Author RSLT supervised the research works and drafted and finalized the manuscript with SB and RPC.

\section{Additional material}

\section{Additional file 1}

Ethnomedicinal plants used by the people of Manang District, Central Nepal. An alphabetical listing of local medicinal plants by species, with family, voucher number and local vernacular name mentioned, as well as a detailed description of preparation and use. ${ }^{*}$ indicates species not previously known for its medicinal use in Manang

Click here for file

[http://www.biomedcentral.com/content/supplementary/17464269-2-41-S1.doc]

\section{Acknowledgements}

The authors (SB and RPC) are thankful to NUFU (The Norwegian Council for Higher Education Programme for Development Research and Education)/Norway and Volkswagen Foundation/Germany for providing financial support for the field work. We are grateful to the peoples of Manang district of Nepal for providing us with their valuable ethnobotanical information and co-operation, without which this work would not have been possible. We thankfully acknowledge Annapurna Conservation Area project (ACAP) for providing research permission for the field work. We also appreciate the comments and suggestions of the reviewers who helped to shape the final version of this manuscript.

\section{References}

I. Bhattarai NK: Traditional Medicine, Medicinal plants and biodiversity Conservation in the global and Nepalese contexts. Plant Research 1998, I( I):22-31.

2. HMG/N: Population of Nepal: Population Census 2002. His Majesty's Government of Nepal, National Planning Commission Secretariat, Central Bureau of Statistics, and United Nations Population Fund; 2002.

3. Gillam S: The traditional healer as village health worker. Journal of the Institute of medicine 1989, I I:67-76.

4. Bhattarai NK: Folk medicinal use of plants for respiratory complaints in Central Nepal. Fitoterapia 1993, 64(2): 163-170. 
5. Lama YC, Ghimire SK, Thomas YA: Medicinal plants of Dolpo: Amchis knowledge and conservation. WWF Nepal Program, Kathmandu, Nepal; 200I.

6. Manandhar NP: Ethnobotanical notes on certain medicinal plants used by Tharus of Dang-Deokhuri District, Nepal. International Journal of Crude Drug Research 1985, 23(4): I53-I59.

7. Manandhar NP: Ethnobotany of Jumla District, Nepal. International Journal of Crude Drug Research 1986, 24(2):8I-89.

8. Manandhar NP: An Ethnobotanical profile of Manang Valley, Nepal. J Econ Tax Bot 1987, 10:207-2/3.

9. Manandhar NP: Medicinal plants used by Chepang tribes of Makawanpur District, Nepal. Fitoterapia 1989, 60(I):6I-68.

10. Manandhar NP: Useful Wild Plants of Nepal. FranzSteiner Verlag Weisbaden GMBH, Stuttgart Germany; 1989.

II. Manandhar NP: An ethnobotanical survey of herbal drugs of Kaski District, Nepal. Fitoterapia 1994, 65(I):7-13.

12. Manandhar NP: Plants and People of Nepal. Timber Press, Inc., The Haseltine Building, Portland, Oregon 9 U.S.A; 2002.

13. Rajbhandari KR: Ethnobotany of Nepal. Ethnobotanical society of Nepal (ESON) I 2001.

14. Pohle P: Useful Plants of Manang District: A contribution to the Ethnobotany of the Nepal-Himalaya. Franz Steiner Verlag Wiesbaden GMBH, Stuttgart; 1990.

15. Spengen Van W: The Nyishangba of Manang : Geographical perspectives on the rise of Nepalese trading Community. Kailash 1987, 1 3:131-278.

16. Pohle $P$ : The adaptation of house settlement to high altitude environment - a study of the Manang district in the NepalHimalaya. Journal of the Nepal Research Centre 1988, VIII:.

17. CBS/ICIMOD/SNV-Nepal: Districts of Nepal - Indicators of Development. Central Bureau of Statistics (CBS), Nepal, International Centre for Integrated Mountain Development (ICIMOD), and SNV-Nepal; 2003.

18. Mayewski PA, Jeschke PA: Himalayan and Trans- Himalayan glacier fluctuation since AD 18 I2. Arctic and Alpine Research 1979, I I:267-287.

19. Polunin O, Stainton A: Flowers of the Himalaya. Oxford Press, New Delhi, India; 1984.

20. Stainton A: Flowers of the Himalayas-A Supplement. Oxford University Press, New Delhi, India; 1988.

21. Grierson AJC, Long DG: Flora of Bhutan Vol. I \& II, Part I-III. Royal Botanic Garden, Edinburgh and Royal Government of Bhutan: 1983-2000

22. Adhikari MK: Morels and their production in natural environment of Jumla district, Nepal. Banko Janakari 2000, I (1): I I- I4.

23. Bista MS, Adhikari MK, Rajbhandari KR: Flowering plants of Nepal (Phanerogams) 18. HMGN, Bull Dept Res 200I.

24. Hara H, Stearn WT, Williams LHJ I: An Enumeration of the Flowering Plants of Nepal. British Museum of Natural History, London; 1978.

25. Hara H, Williams LH] II: An Enumeration of the Flowering Plants of Nepal. British Museum of Natural History, London; 1979.

26. Hara H, Charter AO, Williams LHJ III: An Enumeration of the Flowering plants of Nepal. British Museum of Natural History, London; 1982.

27. Press JR, Shrestha KK, Sutton DA: Annotated Checklist of the flowering Plants of Nepal. Natural History Museum, London and Central Department of Botany, Tribhuvan University, Kathmandu; 2000.

28. Kletter C, Kricchbaum M: Tibetan Medicinal Plants. MedPharm GmbH Scientific Publishers, Birkenwaldstr, Stuttgart, Germany; 200I.

29. Rajbhandari TK, Joshi NR, Shrestha T, Joshi SKG, Achraya B: Medicinal Plants of Nepal for Ayurvedic Drugs. HMGN, Natural Products development division, Thapatali, Kathmandu, Nepal; 1995.

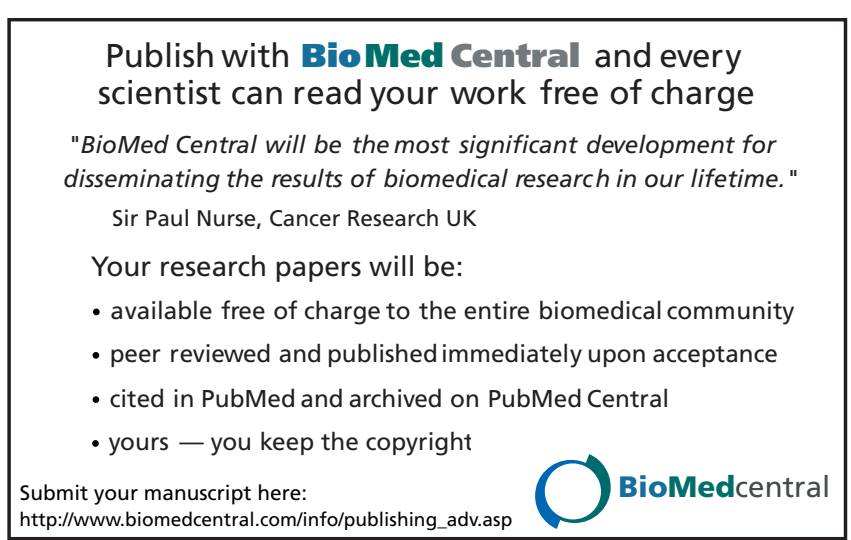

